\title{
Heavy Ion Microbeam- and Broadbeam-Induced Transients in SiGe HBTs
}

Jonathan A. Pellish, Member, IEEE, Robert A. Reed, Senior Member, IEEE, Dale McMorrow, Member, IEEE, Gyorgy Vizkelethy, Member, IEEE, Veronique Ferlet-Cavrois, Senior Member, IEEE,

Jacques Baggio, Member, IEEE, Olivier Duhamel, Kurt A. Moen, Graduate Student Member, IEEE,

Stanley D. Phillips, Graduate Student Member, IEEE, Ryan M. Diestelhorst, Graduate Student Member, IEEE, John D. Cressler, Fellow, IEEE, Akil K. Sutton, Member, IEEE, Ashok Raman,

Marek Turowski, Senior Member, IEEE, Paul E. Dodd, Senior Member, IEEE, Michael L. Alles, Member, IEEE,

Ronald D. Schrimpf, Fellow, IEEE, Paul W. Marshall, Member, IEEE, and Kenneth A. LaBel, Member, IEEE

\begin{abstract}
SiGe HBT heavy ion-induced current transients are measured using Sandia National Laboratories' microbeam and high- and low-energy broadbeam sources at the Grand Accélérateur National d'Ions Lourds and the University of Jyväskylä. The data were captured using a custom broadband IC package and real-time digital phosphor oscilloscopes with at least $16 \mathrm{GHz}$ of analog bandwidth. These data provide detailed insight into the effects of ion strike location, range, and LET.
\end{abstract}

Index Terms -SiGe HBT, heavy ion, transient, real-time oscilloscope

\section{INTRODUCTION}

$\mathbf{H}$ IGH-RELIABILITY applications designed for use in space may employ silicon-germanium heterojunction bipolar transistor (SiGe HBT) technology, like the one shown in Fig. 1, because they offer both performance and total ionizing dose benefits over standard silicon complementary metal oxide semiconductor process technologies and still allow

Manuscript received 17 July 2009. This work was supported in part by the NASA Electronic Parts and Packaging Program, the NASA Radiation Hardened Electronics for Space Environments project, the Defense Threat Reduction Agency Radiation Hardened Microelectronics Program under IACRO \#08-4343I to NASA, the Georgia Electronic Design Center, the Naval Research Laboratory, the Commissariat à 1'Énergie Atomique, an AFOSR DURIP to Vanderbilt University, and Sandia National Laboratories. Sandia is a multiprogram laboratory operated by Sandia Corporation, a Lockheed Martin Company, for the United States Department of Energy's National Nuclear Security Administration under Contract DE-AC04-94AL85000.

J. A. Pellish and K. A. LaBel are with the Flight Data Systems and Radiation Effects branch, NASA Goddard Space Flight Center, Code 561.4, 8800 Greenbelt RD, Greenbelt, MD 20771 USA. Email: jonathan.a.pellish@nasa.gov.

R. A. Reed, M. L. Alles, and R. D. Schrimpf are with the Department of Electrical Engineering and Computer Science, Vanderbilt University, VU Station B \#351824, 2301 Vanderbilt PL, Nashville, TN 37235 USA.

D. McMorrow is with the Naval Research Lab, Code 6812, 4555 Overlook AVE, SW, Washington, DC 20375 USA.

G. Vizkelethy and P. E. Dodd are with Sandia National Laboratories, Albuquerque, NM 87185 USA.

V. Ferlet-Cavrois, J. Baggio, and O. Duhamel are with the CEA, DAM, DIF, F-91297 Arpajon, France.

K. A. Moen, S. D. Phillips, R. M. Diestelhorst, and J. D. Cressler are with the School of Electrical and Computer Engineering, Georgia Institute of Technology, 777 Atlantic DR, NW, Atlanta, GA 30332 USA.

A. K. Sutton is with the IBM Semiconductor Research and Development Center, 2070 Rte 52 MS 32A, Hopewell Junction, NY 12533

A. Raman and M. Turowski are with CFD Research Corporation, 215 Wynn DR, Huntsville, AL 35805 USA.

P. W. Marshall is a NASA consultant, Brookneal, VA 24528 USA.

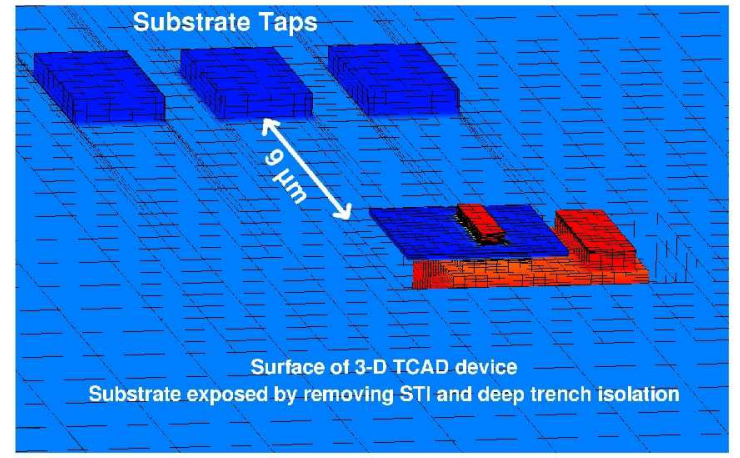

(a) 3-D TCAD model of IBM 5AM SiGe HBT DUT

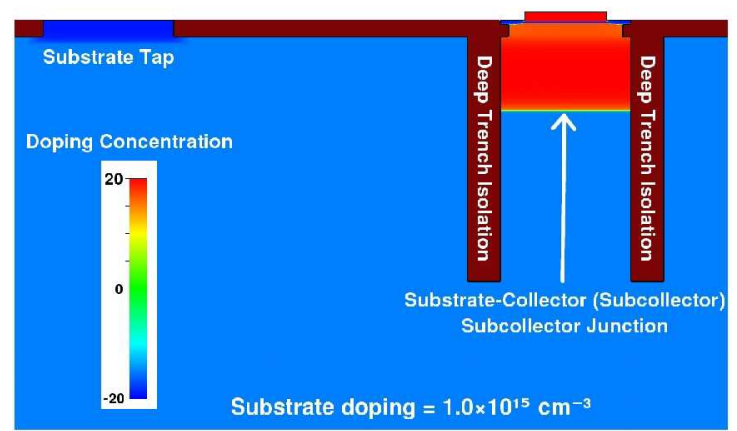

(b) 2-D slice of 3-D TCAD model of IBM 5AM SiGe HBT DUT.

The doping concentration scale is logarithmic.

Fig. 1. 3-D and 2-D renderings of the npn IBM 5AM SiGe HBT device under test for the heavy ion experiments. Fig. 1(a) shows a 3-D model with emitter area $A_{\mathrm{E}}=0.5 \times 2.5 \mu \mathrm{m}^{2}$. The $3-\mathrm{D}$ geometry was extracted from the GDSII file of the test structures. Fig. 1(b) shows a 2-D slice through the short dimension of the device (emitter width) shown in Fig. 1(a). Note the deep trench isolation, subcollector-substrate junction, and the lightly-doped p-type substrate. The deep trench isolation is approximately $7 \mu \mathrm{m}$ in depth, $1 \mu \mathrm{m}$ thick, and has inner areal dimensions of $4.1 \times 4.3 \mu \mathrm{m}^{2}$.

monolithic fabrication [1], [2]. The majority of SiGe HBT applications tested within the radiation effects community have been high-speed serial shift registers [3]-[7]. Because the data rates of these circuits regularly exceed $1 \mathrm{Gbit} / \mathrm{s}$, the detailed characteristics of ion-induced current transients become important and are necessary for a full understanding of the behavior in a particular radiation environment [8]-[10].

This paper presents heavy ion microbeam positioncorrelated data, coupled with a range of broadbeam energies 


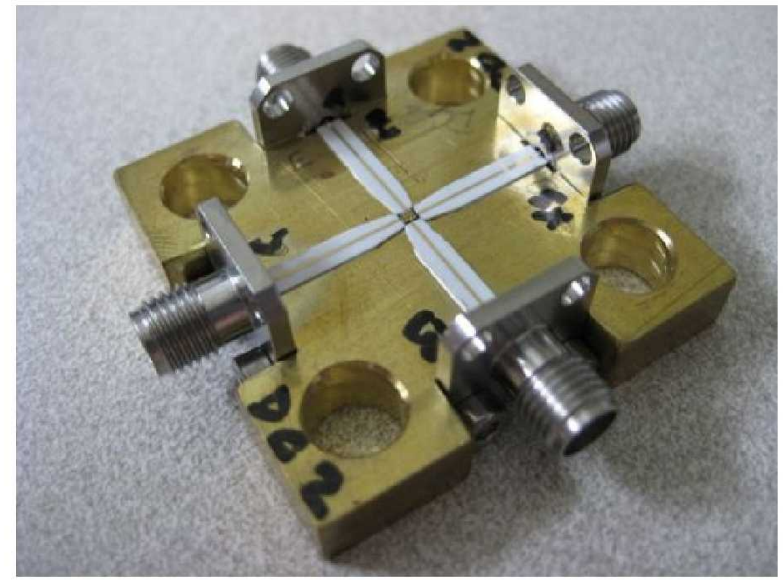

Fig. 2. An example of a high-speed package used for the heavy ion experiments described here and for earlier pulsed laser experiments [12] This image shows the brass ground plane, the bulkhead $2.9 \mathrm{~mm}$ coaxial connectors, microstrip transmission lines, and the DUT tile in the center. The brass substrate is approximately $3.8 \mathrm{~cm}$ on a side. The DUT tile in the middle is $1 \mathrm{~mm}^{2}$.

and linear energy transfers (LETs), providing detailed devicelevel data on the temporal profile of ion-induced current transients in this important semiconductor technology. These results are consistent with previous pulsed-laser measurements on SiGe HBTs [11], [12] as well as broadbeam data conclusions, including those regarding cross section effects at low LET and grazing angles [3]-[5], [13]-[15]. The different LETs and particle energies show the consequences of heavy ion charge generation and collection in devices with lightly-doped substrates. These data capture essential information required for accurate device physics modeling.

\section{EXPERIMENTAL Details}

We collected single-event current transients at three different facilities: Sandia National Laboratories' (SNL) Ion Beams Materials Research Lab using a 6 MV EN tandem Van de Graaff microbeam, the Department of Physics at the University of Jyväskylä (JYFL) using a K-130 cyclotron, and the Grand Accélérateur National d'Ions Lourds (GANIL) high-energy beamline. The microbeam data gathered at SNL are based on $36 \mathrm{MeV}{ }^{16} \mathrm{O}$ and include relative $x y$-coordinates of each ion strike based on the microbeam coordinate system. The data collected at JYFL and GANIL are broadbeam data, gathered without knowledge of ion strike location, but possess higher energy, the possibility of angled irradiation, and a wide selection of LETs. JYFL heavy ion exposures include $9.3 \mathrm{MeV} / \mathrm{u}^{20} \mathrm{Ne},{ }^{40} \mathrm{Ar},{ }^{82} \mathrm{Kr}$, and ${ }^{131} \mathrm{Xe}$. The ${ }^{40} \mathrm{Ar}$ irradiations at JYFL were performed at a tilt of $60^{\circ}$ in addition to normal incidence. We performed irradiations at GANIL using 45.5 MeV/u ${ }^{136} \mathrm{Xe}$. We conducted all exposures at normal incidence unless otherwise noted.

The device under test (DUT) is an IBM 5AM SiGe HBT with emitter area $A_{\mathrm{E}}=0.5 \times 2.5 \mu \mathrm{m}^{2}$ and inner deep trench isolation areal dimensions of $4.1 \times 4.3 \mu \mathrm{m}^{2}$. It was mounted in a custom high-speed package with four $2.9 \mathrm{~mm}$ coaxial bulkhead connectors joined to microstrip transmission lines.
The DUT was wire bonded to the microstrips using $1 \mathrm{mil}$ gold wire. Several articles describe this type of package and the device in more detail [1], [12], [16]-[19]. A picture of a completed package used for this work is shown in Fig. 2. At JYFL and GANIL, the transients on the base and collector were measured and recorded with a Tektronix DPO71604A $16 \mathrm{GHz}$ (40 GS/s), real-time digital phosphor oscilloscope (DPO). At SNL, substrate, collector, and base, transients were measured and recorded with a Tektronix DPO72004 $20 \mathrm{GHz}$ (50 GS/s), real-time DPO. The oscilloscope triggered on the collector channel for all experiments. At the SNL microbeam, the trigger was $\leq|5 \mathrm{mV}|$. At JYFL and GANIL, the trigger was $\leq|15 \mathrm{mV}|$. The experiments focused on three bias conditions for the DUT: (Case 1) $V_{\mathrm{Sub}}=-4 \mathrm{~V}$, (Case 2) $V_{\mathrm{C}}=3 \mathrm{~V}$, and (Case 3) $V_{\mathrm{Sub}}=-3 \mathrm{~V}$. If the terminal is not listed, it is grounded. This means for Case 1 that $V_{\mathrm{E}, \mathrm{B}, \mathrm{C}}=0 \mathrm{~V}$.

The bias conditions - Cases 1, 2, and 3 - are designed to mimic past experiments with SiGe HBT-based circuits, e.g. [3]-[5], [13], [14], [20], respecting the fact this is a single, isolated transistor. Typical current mode logic bipolar circuit design places the collector at ground and the emitter and substrate large negative voltages, $V_{\mathrm{ee}}=-3.3 \mathrm{~V}$ and $V_{\text {Sub }}$ between -3 and $-5 \mathrm{~V}$ for instance [5]. $+3 \mathrm{~V}$ on the collector is intended to represent an extreme bias for a BiCMOS-like application where the substrate would be grounded. $-3 \mathrm{~V}$ on the substrate is a direct comparison to $+3 \mathrm{~V}$ on the collector, because the same potential is dropped across the subcollector junction. However, the positive voltage collector biasing scheme (Case 3 ) changes the device response by making $V_{\mathrm{CB}}$ non-zero.

The external circuit components and lumped elements are shown in Fig. 3 as a schematic diagram, with only those attached to the collector node shown for clarity. In the actual experiments, all device terminals receive analogous passive components. The values of the passive components are as follows, assuming a 48 in length of Gore $0 \mathrm{~K}$ coaxial cable: die pad capacitance $C_{\text {pad }}=59 \mathrm{fF}$, bondwire inductance $L_{\mathrm{bw}} \approx 1 \mathrm{nH}$, distributed series inductance $L_{\mathrm{s}}=187 \mathrm{nH} / \mathrm{m}$, distributed shunt capacitance $C_{\mathrm{s}}=78 \mathrm{pF} / \mathrm{m}$, distributed conductance $G_{\mathrm{s}}=110 \mu \mho /(\mathrm{GHz} \cdot \mathrm{m})$, distributed resistance $R_{\mathrm{s}} \approx 12 \Omega / \mathrm{m}$ at $20 \mathrm{GHz}$, bias tee inductance $L_{\text {tee }}=1.5 \mathrm{mH}$, bias tee capacitance $C_{\text {tee }}=0.22 \mu \mathrm{F}$, oscilloscope capacitance $C_{\mathrm{osc}}=0.35 \mathrm{pF}$, and oscilloscope resistance $R_{\mathrm{osc}}=50 \Omega$. The oscilloscope capacitance, in parallel with a $50 \Omega$ resistor, was calculated to yield the $19 \mathrm{ps}(10 \%-90 \%)$ rise time of the Tektronix DPO72004.

\section{RESULTS}

Figs. 4(a) and 4(b) plot the peak base and collector currents as a function of position obtained from a $36 \mathrm{MeV}{ }^{16} \mathrm{O}$ timeresolved ion beam-induced charge (TRIBIC) [21] scan on an IBM 5AM SiGe HBT under the bias conditions of Case 1. The scan area is $20 \mu \mathrm{m} \times 20 \mu \mathrm{m}$ with $200 \mathrm{~nm}$ steps and a spatial resolution of $<1 \mu \mathrm{m}$. The scans produced approximately 400 data points based on a $-4 \mathrm{mV}$ trigger on the collector. As observed in previous laser testing results [12], the peak collector responses are confined to the base-collector junction, 


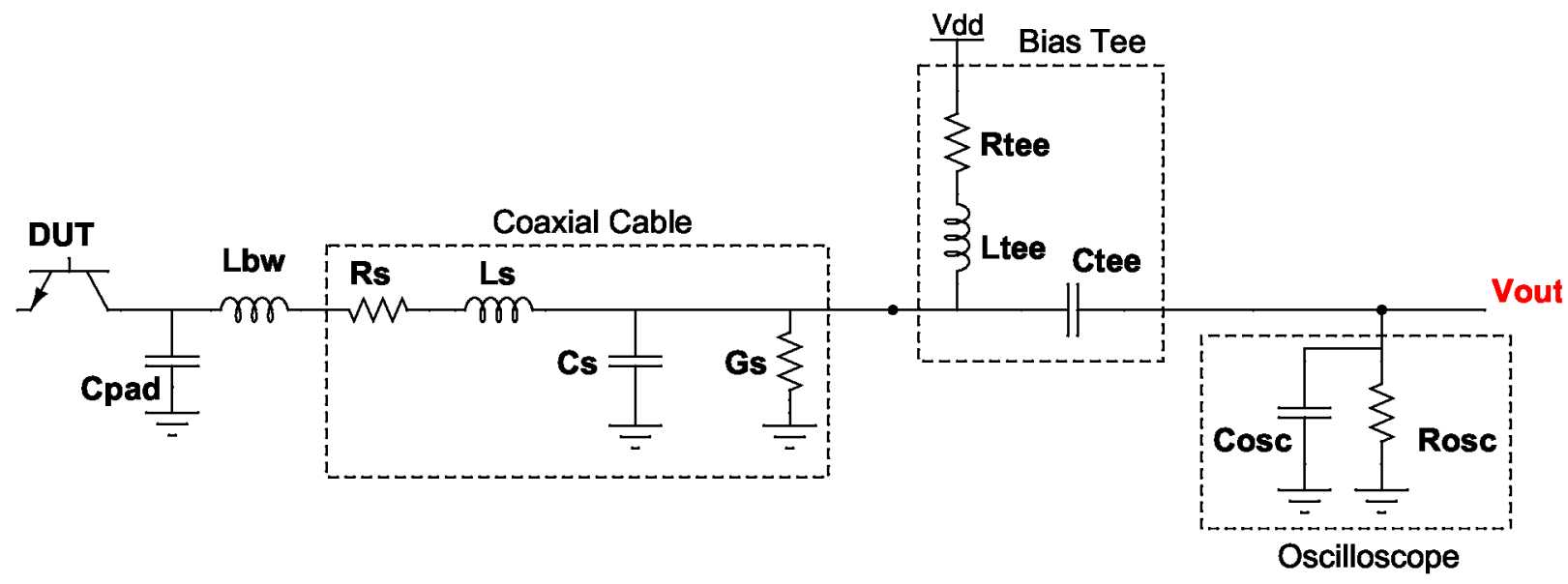

Fig. 3. A schematic diagram showing external parasitic components present for all heavy ion transient measurements. The two critical components are the bondwire inductance $\left(L_{\mathrm{bw}} \approx 1 \mathrm{nH}\right)$ and the oscilloscope RC-network $\left(C_{\mathrm{osc}}=0.35 \mathrm{pF}\right.$ and $\left.R_{\mathrm{osc}}=50 \Omega\right)$.

which is located in Fig. 4(b) on the $y$-axis between 0 and $4 \mu \mathrm{m}$ and between 0 and $2 \mu \mathrm{m}$ on the $x$-axis. The oscilloscope triggers on the collector channel only when the ion strikes in or near the area enclosed by the deep trench isolation. Coupling this microbeam information with the peak transient current and integrated transient charge enables position correlation of the broadbeam strikes in reference to the DUT's physical structures.

In Fig. 5(a), with a $+3 \mathrm{~V}$ bias on the collector (Case 2 ), instead of a $-3 \mathrm{~V}$ bias on the substrate (Case 3) as shown in Fig. 5(b), the collector current transients within the base-collector junction are magnified by more than a factor of two. The magnification of the base-collector junction transients in Case 2 is presumably due to a combination of the Early effect and avalanche multiplication [12]. The data in each of these figures, 5(a) and 5(b), represents the same voltage dropped across the subcollector junction, producing an equivalent depletion layer. The nominal transient peak current of $0.5 \mathrm{~mA}$ remains the same for strikes that do not cross the base-collector junction.

Fig. 6 shows two of the larger base and collector current transients obtained from the JYFL broadbeam heavy ion results, demonstrating the significance of ion LET on the production of current transients. Based on knowledge of the microbeam data already presented, the transients shown in Fig. 6 are the result of direct hits to the active region of the device; each pair shown are correlated events from a single ion. The average neon transient had a peak magnitude of $0.25 \pm 0.04 \mathrm{~mA}$ (base) and $0.90 \pm 0.04 \mathrm{~mA}$ (collector). For xenon, the average peak magnitudes are $0.57 \pm 0.08 \mathrm{~mA}$ (base) and $2.9 \pm 0.19 \mathrm{~mA}$ (collector). These transients were captured with a $-15 \mathrm{mV}$ trigger on the collector terminal, which is larger than the trigger used at SNL due to electrical noise encountered at the JYFL facility.

As expected, the xenon transient in Fig. 6 produces more charge resulting in large transients on both the collector and base terminals. The plateau in the xenon collector transient, and large amount of collected charge, is due to the fact that the device terminals are tied to external voltage sources and capacitors. Connecting the DUT to a circuit that allowed the voltage to collapse under high current draw would modify the plateau and perhaps shorten the transient. However, the plateau suggests some form of saturation, which is likely due to systematic effects, such as the bias tee capacitor. The neon transients are similar to the SNL microbeam transients in Fig. 4 and compare well to previous pulsed laser testing [12], indicating data consistency and LET proportionality.

The JYFL argon results, shown in Figs. 7 (a) and 7(b), at normal incidence and a $60^{\circ}$ tilt confirm that increasing the angle of incidence relative to the device surface normal produces fewer transients, based on an oscilloscope trigger value of $-15 \mathrm{mV}$ on the collector. At normal incidence with $-4 \mathrm{~V}$ on the substrate, the oscilloscope captured 50 transients after a fluence of $3.85 \times 10^{7} \mathrm{~cm}^{-2}$. However, at a tilt of $60^{\circ}$ with the same bias conditions, only 16 events were measured after a fluence of $1.94 \times 10^{8} \mathrm{~cm}^{-2}$, a 16x decrease in cross section. This result confirms, at the device-level, the effect of cross-section decrease with increasing ion angle for low LET particles, observed in many previous broadbeam tests of SiGe HBT circuit applications [3]-[5] and described via TCAD simulation [15], [22]. It is critical to understand this effect in order to calculate event rates for space-based applications.

The $60^{\circ}$ angle of incidence transients have a much larger distribution of peak current magnitude and collected charge, the smaller cross section notwithstanding. The smallest transients measured in Fig. 7(b) correspond to a peak measured voltage of approximately $-17 \mathrm{mV}$, just $2 \mathrm{mV}$ above the $-15 \mathrm{mV}$ trigger. The trend with the argon data sets suggests that lowering the trigger level would show a majority of the transient peaks between approximately 0.25 and $0.5 \mathrm{~mA}$.

The issue of ion range in the substrate, below the active region, is important for devices fabricated directly on lightlydoped substrates, such as bulk SiGe HBTs and other bipolar devices. This is a key point for space applications, which will be exposed to a variety of long-range heavy ions. Fig. 8 compares the current transients induced by two different particles with approximately the same LET, but different ranges. The 9.3 MeV/u ${ }^{82} \mathrm{Kr}$ ion has a range of approximately $90 \mu \mathrm{m}$ 


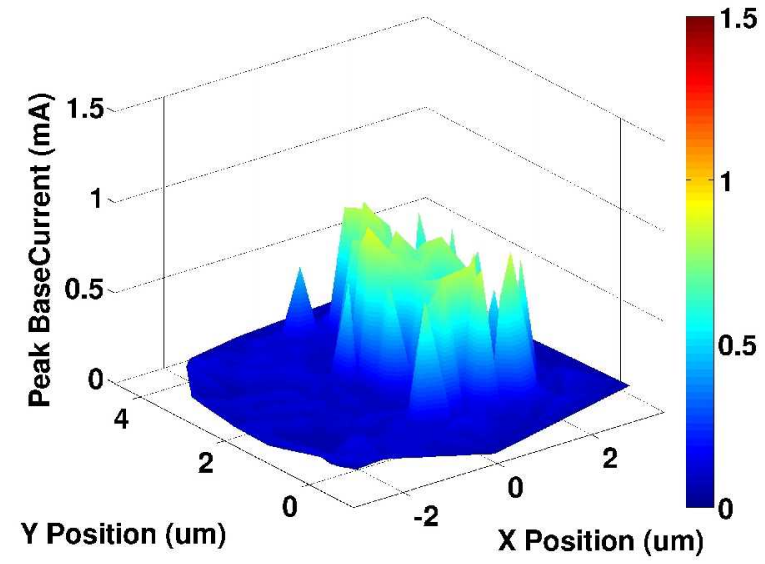

(a) Base terminal current transient peaks for one microbeam scan. The device is biased according to Case 1 , where $V_{\mathrm{Sub}}=-4 \mathrm{~V}$ and all other terminals are grounded.

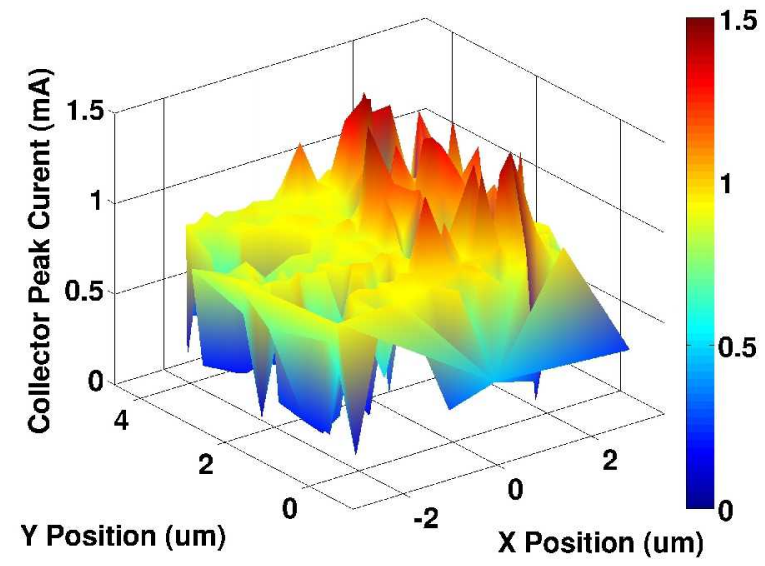

(b) Collector terminal current transient peaks for one microbeam scan. The device is biased according to Case 1, where $V_{\mathrm{Sub}}=-4 \mathrm{~V}$ and all other terminals are grounded.

Fig. 4. $36 \mathrm{MeV}{ }^{16} \mathrm{O}$ TRIBIC scan on an IBM 5AM SiGe HBT with $V_{\text {Sub }}=-4 \mathrm{~V}$ (Case 1) and all other terminals grounded. The IBM 5AM SiGe HBT has an emitter area of $0.5 \times 2.5 \mu \mathrm{m}^{2}$ and inner deep trench isolation dimensions of $4.1 \times 4.3 \mu \mathrm{m}^{2}$. The peak current for the collector and base terminals is plotted. The collector transients were scaled by -1 to yield a positive scale. The jagged surface in the data is due to the delaunization algorithm's interpretation of the irregular $x y$-spacing.

in the substrate and an LET of $32\left(\mathrm{MeV} \cdot \mathrm{cm}^{2}\right) / \mathrm{mg}$. The $45.5 \mathrm{MeV} / \mathrm{u}{ }^{136} \mathrm{Xe}$ ion has a range sufficient to penetrate the substrate and an LET of $27\left(\mathrm{MeV} \cdot \mathrm{cm}^{2}\right) / \mathrm{mg}$. Both ranges account for $15 \mu \mathrm{m}$ of back-end-of-line overburden. For the krypton strike, the device collects approximately $5.0 \%$ of the total $27 \mathrm{pC}$ of generated charge. In the case of xenon, the device collects about $2-3 \%$ of the $96 \mathrm{pC}$ generated by the ion assuming a $300 \mu \mathrm{m}$ substrate. However, comparing the integrated charge and transient current peaks in Fig. 8 shows that the xenon strike results in almost a $2 \mathrm{x}$ increase over the krypton result in both metrics. The average collector peak magnitude current for $45.5 \mathrm{MeV} / \mathrm{u}$ xenon strikes to the DUT is $1.6 \pm 0.06 \mathrm{~mA}$ - compared to krypton at $0.81 \pm 0.15 \mathrm{~mA}$. While the krypton and xenon collector current transients in Fig. 8 are both large compared to their averages, the $2 x$ increase

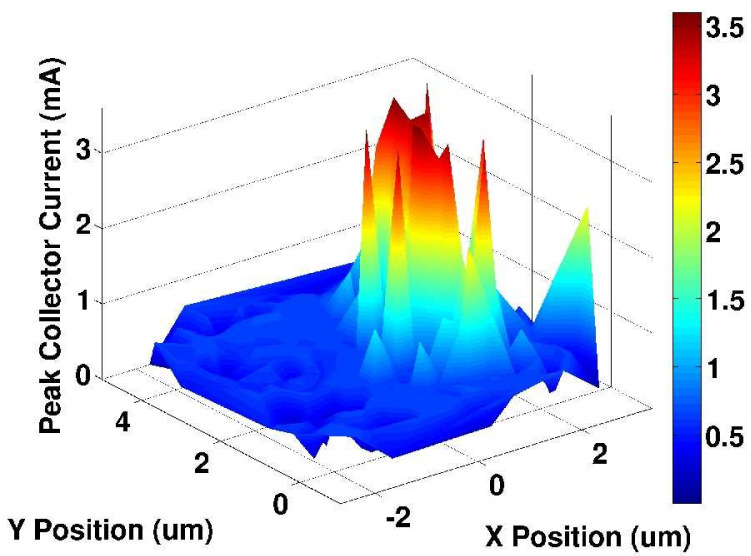

(a) Collector terminal current transient peaks for one microbeam scan. The device is biased according to Case 2, where $V_{\mathrm{C}}=+3 \mathrm{~V}$ and all other terminals are grounded.

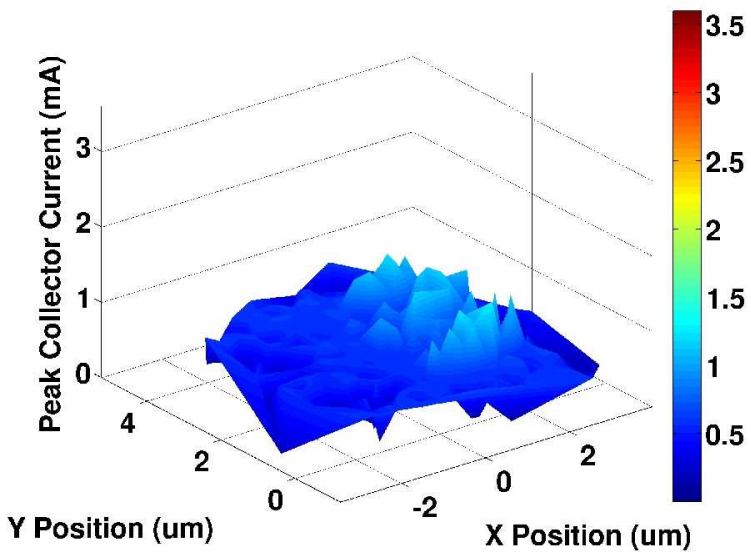

(b) Collector terminal current transient peaks for one microbeam scan. The device is biased according to Case 3, where $V_{\mathrm{Sub}}=-3 \mathrm{~V}$ and all other terminals are grounded.

Fig. 5. $36 \mathrm{MeV}^{16} \mathrm{O}$ TRIBIC scan on an IBM $5 \mathrm{AM}$ SiGe HBT with $V_{\mathrm{C}}=$ $+3 \mathrm{~V}$ (Case 2) in Fig. 5(a) and with $V_{\text {Sub }}=-3 \mathrm{~V}$ (Case 3) in Fig. 5(b). These data are from the same DUT used for data collection in Fig. 4.

in collected charge is still supported by the peak current magnitude averages assuming that peak current is proportional to collected charge.

The additional xenon collected charge in Fig. 8 occurs over a short period of time, indicating that it is related to the equipotential deformation of the subcollector junction depletion region [12]. Since the tail of each transient is coincident past about $1.5 \mathrm{~ns}$, it is unlikely that the single-event current is related to diffusion transport. This implies that the long range of the high-energy xenon ion causes a more substantial deformation of the subcollector depletion region resulting in a larger transient and more charge collection. Furthermore, it also highlights the importance of the substrate for bulk SiGe HBT single-event effects [23].

The concept of ion track structure arises when considering data like those shown in Fig. 8. Many papers cover the topic of ion track structure based on the range of high-energy $\delta$ rays [24]-[29]. The recent work of M. Murat et al. [30] uses 


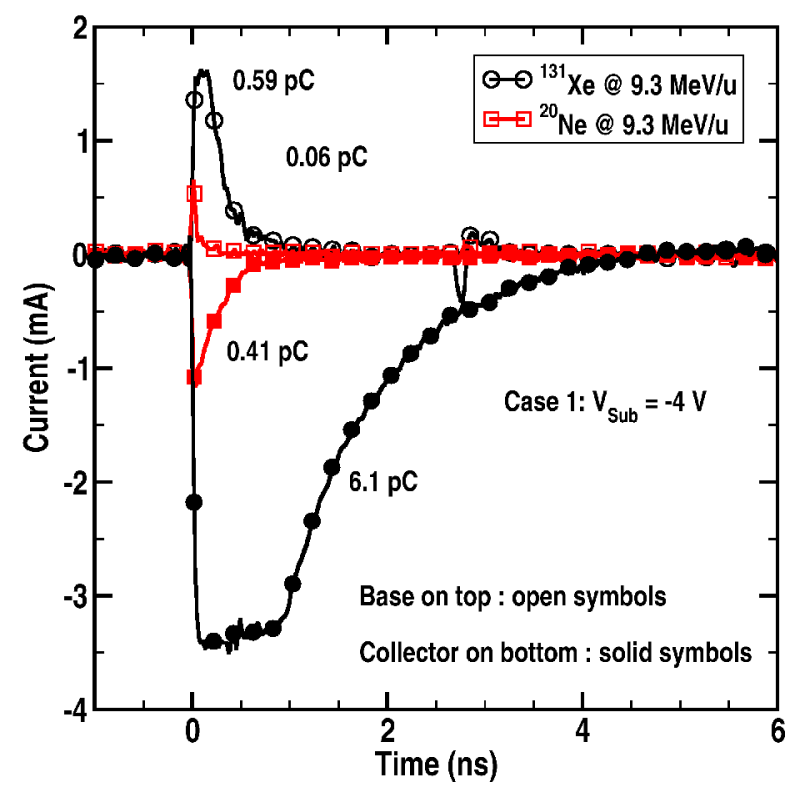

Fig. 6. JYFL - ion LET comparison. Case 1: $V_{\text {Sub }}=-4 \mathrm{~V}$. Neon and xenon transients captured at JYFL demonstrating device response to two extreme LETs, $3.7\left(\mathrm{MeV} \cdot \mathrm{cm}^{2}\right) / \mathrm{mg}$ for the neon ions and $60\left(\mathrm{MeV} \cdot \mathrm{cm}^{2}\right) / \mathrm{mg}$ for the xenon ions; the integrated charge is labeled next to each curve. The neon transients are similar to those measured with the SNL microbeam.

a Monte Carlo code [31] to track the ejected electrons down to thermalization. All of these articles make the point that track structure does matter in certain cases. While track structure has not been confirmed as a contributing factor to the difference between the JYFL and GANIL data in Fig. 8, it cannot be ruled out. These track structure effects can contribute to depletion region deformation, potential collapse, and current transient production [29], [32], [33].

The JYFL and GANIL heavy ion data in Fig. 8 also highlight why simplified rate prediction models for SiGe HBTs carry inherent flaws and increased risk. It is conceptually convenient to model a SiGe HBT by just accounting for the active region of the device, but this is neither sufficient nor correct regardless of whether the ion actually crosses the device junctions. The ion mass, energy, and angle of incidence, the substrate and device surroundings, and the electrical impedance of each device terminal all have significant roles to play. However, at the present time it is only possible to achieve this level of accuracy by incorporating Monte Carlo radiation transport [34], [35] and 3-D TCAD, which is not always practical.

Finally, several comments have been made regarding the oscilloscope trigger value, specifically the effects of facility noise and in turn how the trigger value affects transient measurements. A lower trigger offset results in more captured transients, and perhaps measurement of transients originating from strikes outside the deep trench isolation. A trigger level of $|2-5| \mathrm{mV}$ is ideal, but not always possible. Even at levels this low, it is still possible to miss some slow transients with sufficient integrated charge because the amplitude is too small. This issue is partially circumvented by pulsed laser testing since in that case the repetition rate of the radiation is a known

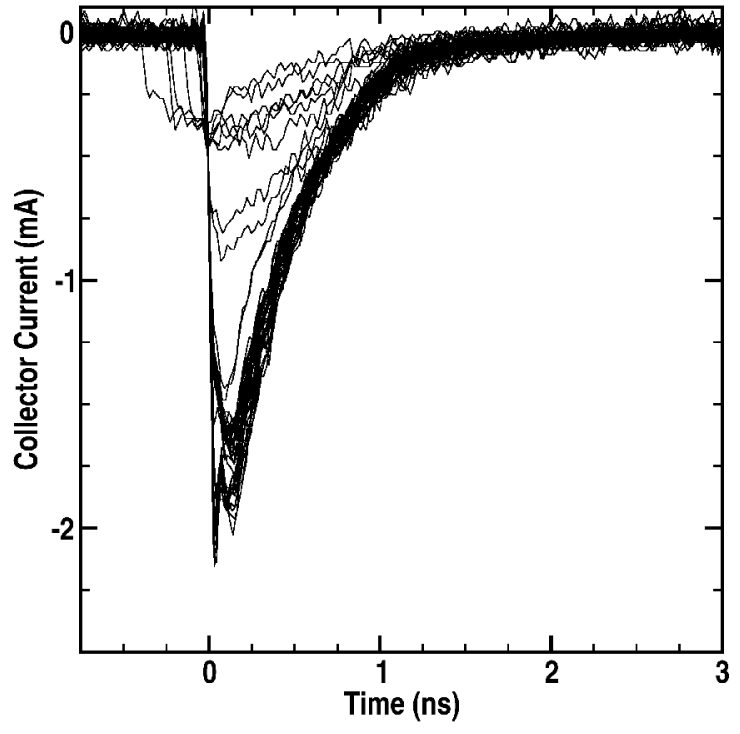

(a) JYFL $-{ }^{40} \mathrm{Ar}$ at $0^{\circ}$. Case 1: $V_{\mathrm{Sub}}=-4$ V. 50 total transients measured and shown. $\Phi=3.85 \times 10^{7} \mathrm{~cm}^{-2} ; \sigma=1.3 \times 10^{-6} \mathrm{~cm}^{2}$

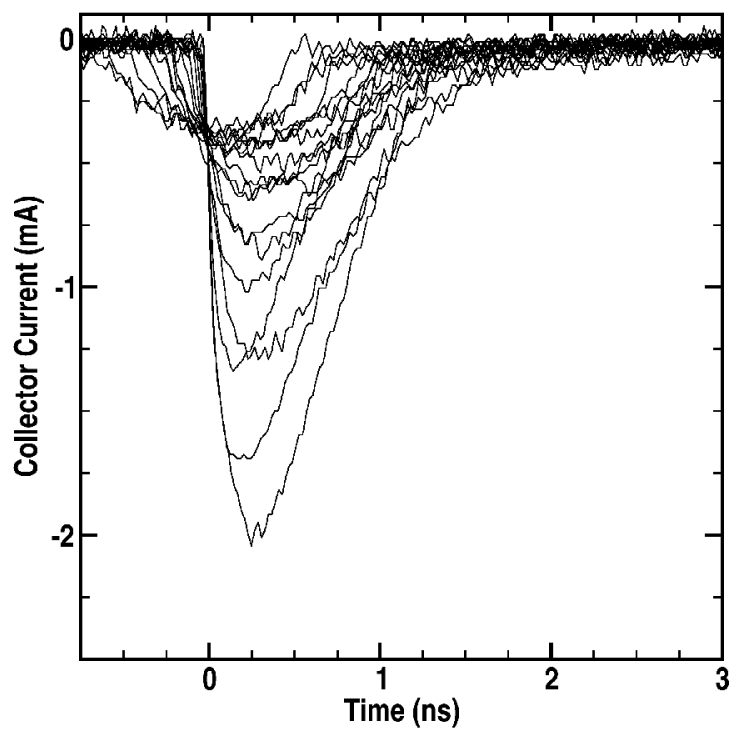

(b) JYFL $-{ }^{40} \mathrm{Ar}$ at $60^{\circ}$. Case 1: $V_{\mathrm{Sub}}=-4 \mathrm{~V} .16$ total transients measured and shown. $\Phi=1.94 \times 10^{8} \mathrm{~cm}^{-2} ; \sigma=8.2 \times 10^{-8} \mathrm{~cm}^{2}$

Fig. 7. $9.3 \mathrm{MeV} / \mathrm{u}^{40} \mathrm{Ar}$ ion transients from JYFL. Fig. 7(a) shows the fifty transients captured after a normally incident fluence of $3.85 \times 10^{7} \mathrm{~cm}^{-2}$. Fig. 7(b) shows the only 16 measurable events at $60^{\circ}$ after a fluence of $1.94 \times 10^{8} \mathrm{~cm}^{-2}$. Both irradiations were done with a $-15 \mathrm{mV}$ trigger on the collector, representing a $16 x$ difference in cross section.

quantity, and in some cases dictated as an independent variable by the experimenter [36]. The timing generator controlling the laser pulses can be used as an external trigger input to the oscilloscope. This enables the measurement of low-magnitude, long-duration transients. Such a setup is required if using a sampling oscilloscope, but the very lack of this requirement for real-time oscilloscopes is what makes them valuable for heavy ion measurements. Accelerator delivery of ions to a target is a stochastic process and requires a real-time oscilloscope with an autonomous trigger. 


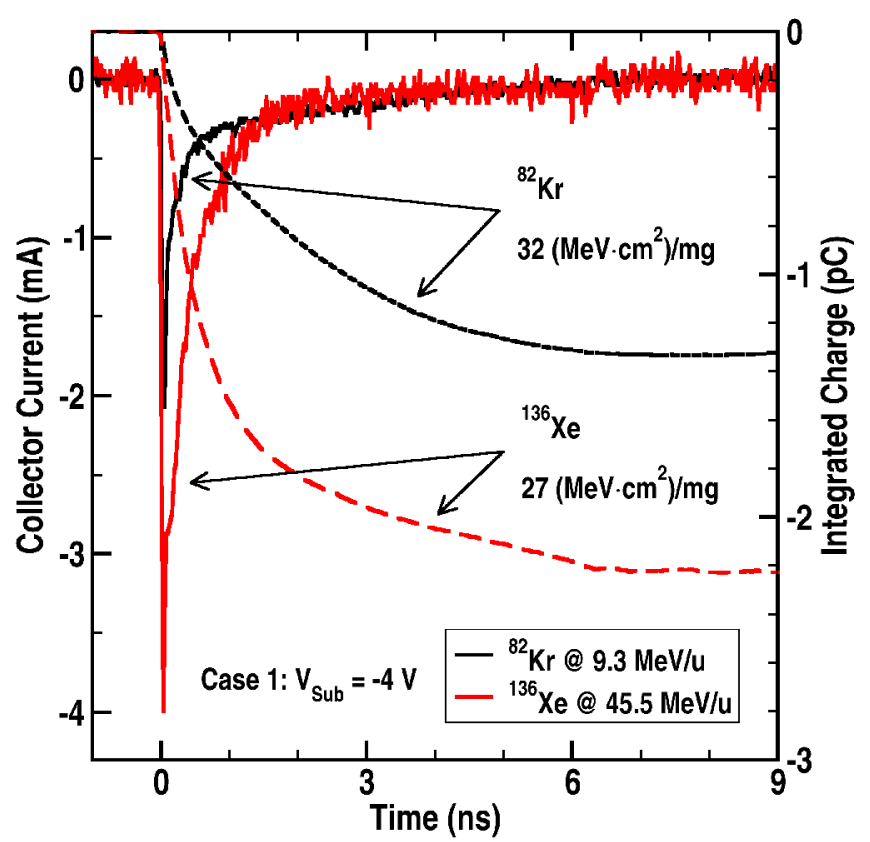

Fig. 8. GANIL $v s$. JYFL - ion range comparison. Case 1: $V_{\text {Sub }}=-4 \mathrm{~V}$. $45.5 \mathrm{MeV} / \mathrm{u}$ xenon transient measured at GANIL compared to a $9.3 \mathrm{MeV} / \mathrm{u}$ krypton transient measured at JYFL. Though the two ions have similar LETs, they produce different transients and integrated charges. The solid lines are terminal currents plotted relative to the left ordinate; the dashed lines are the integral charge plotted relative to the right ordinate.

\section{CONCLUSION}

These heavy ion current transient data represent a significant improvement to the state-of-the-art understanding of heavy ion-induced charge and transients in SiGe HBTs by using microbeam data to position-correlate broadbeam singleevent current transients. These results complete heavy ion microbeam charge collection and pulsed laser data sets. Previous microbeam data only measured collected charge and previous two-photon pulsed-laser transient measurements cannot be easily correlated to ion LET and ion-specific effects. Taken as a whole and coupled with device simulation, a complete picture of charge generation, transport, and collection in bulk SiGe HBTs is possible.

Much of the future work in the field of single-event current and voltage transient measurements needs to focus on understanding and modeling die-level and external parasitics. This is achieved through electronic design automation and electromagnetic solver tool sets as well as time-domain reflectometry and other vector network analysis. Test vehicles incorporating on-die termination and passive matching networks would help promote maximum coupling between the DUT and transmission system and thereby prevent unnecessary power loss. Understanding the parasitics is critical for any subsequent mixed-mode TCAD simulation and controlling them is necessary for high-quality data.

\section{ACKNOWLEDGMENT}

The authors thank Ari Virtanen, Arto Javanainen, and the RADEF team at the University of Jyväskylä, Finland for the heavy ion beam time. The authors thank Stéphane Guillous, Jean-Marc Ramillon, and the management team at GANIL in Caen, France for access to the high-energy xenon beam time. The authors thank P. Pino of W. L. Gore \& Associates for his help in gathering s-parameter data. The authors also extend thanks Lewis Cohn, Maj. James Fee, and the SiGe team at IBM for their ongoing support.

\section{REFERENCES}

[1] J. D. Cressler, Ed., The Silicon Heterostructure Handbook: materials fabrication, devices, circuits, and applications of SiGe and Si strainedlayer epitaxy. Boca Raton, FL: CRC, 2006.

[2] J. D. Cressler, "SiGe BiCMOS technology: an IC design platform for extreme environment electronics applications," in $45^{\text {th }}$ Annu. Int. Reliability Physics Symp. Phoenix, AZ: IEEE, Apr. 2007, pp. 141149.

[3] P. W. Marshall, M. A. Carts, A. Campbell, D. McMorrow, S. Buchner, R. Stewart, B. Randall, B. Gilbert, and R. A. Reed, "Single event effects in circuit-hardened SiGe HBT logic at gigabit per second data rates," IEEE Trans. Nucl. Sci., vol. 47, no. 6, pp. 2669-2674, Dec. 2000.

[4] R. A. Reed, P. W. Marshall, J. C. Pickel, M. A. Carts, B. Fodness, G. F. Niu, K. Fritz, G. Vizkelethy, P. E. Dodd, T. Irwin, J. D. Cressler, R. Krithivasan, P. Riggs, J. Prairie, B. Randall, B. Gilbert, and K. A. LaBel, "Heavy-ion broad-beam and microprobe studies of single-event upsets in $0.20 \mu \mathrm{m} \mathrm{SiGe} \mathrm{heterojunction} \mathrm{bipolar} \mathrm{transistors} \mathrm{and} \mathrm{circuits,"}$ IEEE Trans. Nucl. Sci., vol. 50, no. 6, pp. 2184-2190, Dec. 2003.

[5] P. W. Marshall, M. Carts, S. M. Currie, R. A. Reed, B. Randall, K. Fritz, K. Kennedy, M. Berg, R. Krithivasan, and C. Siedleck, "Autonomous bit error rate testing at multi-gbit/s rates implemented in a $5 \mathrm{AM} \mathrm{SiGe}$ circuit for radiation effects self test (CREST)," IEEE Trans. Nucl. Sci., vol. 52, no. 6, pp. 2446-2454, Dec. 2005.

[6] R. Krithivasan, P. W. Marshall, M. Nayeem, A. K. Sutton, W.-M. Kuo, B. M. Haugerud, L. Najafizadeh, J. D. Cressler, M. A. Carts, C. J. Marshall, D. L. Hansen, K.-C. M. Jobe, A. L. McKay, G. Niu, R. Reed, B. A. Randall, C. A. Burfield, M. D. Lindberg, B. K. Gilbert, and E. S. Daniel, "Application of RHBD techniques to SEU hardening of thirdgeneration SiGe HBT logic circuits," IEEE Trans. Nucl. Sci., vol. 53, no. 6, pp. 3400-3407, Dec. 2006.

[7] A. K. Sutton, K. Moen, J. D. Cressler, M. A. Carts, P. W. Marshall, J. A. Pellish, V. Ramachandran, R. A. Reed, M. L. Alles, and G. Niu, "Proton-induced SEU in SiGe digital logic at cryogenic temperatures," Solid State Electron., vol. 52, no. 10, pp. 1652-1659, Oct. 2008.

[8] G. Niu, J. D. Cressler, M. Shoga, K. Jobe, P. Chu, and D. L. Harame, "Simulation of SEE-induced charge collection in UHV/CVD SiGe HBTs," IEEE Trans. Nucl. Sci., vol. 47, no. 6, pp. 2682-2689, Dec. 2000.

[9] G. Niu, R. Krithivasan, J. D. Cressler, P. Marshall, C. Marshall, R. Reed, and D. L. Harame, "Modeling of single-event effects in circuit-hardened high-speed SiGe HBT logic," IEEE Trans. Nucl. Sci., vol. 48, no. 6, pp. 1849-1854, Dec. 2001.

[10] X. Wei, T. Zhang, G. Niu, M. Varadharajaperumal, J. D. Cressler, and P. W. Marshall, "3-D mixed-mode simulation of single event transients in SiGe HBT emitter followers and resultant hardening guidelines," IEEE Trans. Nucl. Sci., vol. 55, no. 6, pp. 3360-3366, Dec. 2008.

[11] R. L. Pease, "RHBD analog/mixed-signal devices and circuits," RLP Reasearch, Inc. for ATK-Mission Research, Albuquerque, New Mexico USA, Tech. Rep., Mar. 2006, under contract FA9453-04-C-0208, Subcontract SC-0208-04-0400.

[12] J. A. Pellish, R. A. Reed, D. McMorrow, J. S. Melinger, P. Jenkins, A. K. Sutton, R. M. Diestelhorst, S. D. Phillips, J. D. Cressler, V. Pouget, N. D. Pate, J. A. Kozub, M. H. Mendenhall, R. A. Weller, R. D. Schrimpf, P. W. Marshall, A. D. Tipton, and G. Niu, "Laser-induced current transients in silicon-germanium HBTs," IEEE Trans. Nucl. Sci., vol. 55, no. 6, pp. 2936-2942, Dec. 2008.

[13] D. L. Hansen, P. W. Marshall, R. Lopez-Aguado, K. Jobe, M. A Carts, C. J. Marshall, P. Chu, and S. F. Meyer, "A study of the SEU performance of InP and SiGe shift registers," IEEE Trans. Nucl. Sci., vol. 52, no. 4, pp. 1140-1147, Aug. 2005.

[14] D. L. Hansen, P. Chu, K. Jobe, A. L. McKay, and H. P. Warren, "SEU cross sections of hardened and unhardened SiGe circuits," IEEE Trans. Nucl. Sci., vol. 53, no. 6, pp. 3579-3586, Dec. 2006. 
[15] J. A. Pellish, R. A. Reed, A. K. Sutton, R. A. Weller, M. A. Carts, P. W. Marshall, C. J. Marshall, R. Krithivasan, J. D. Cressler, M. H. Mendenhall, R. D. Schrimpf, K. M. Warren, B. D. Sierawski, and G. F. Niu, "A generalized SiGe HBT single-event effects model for on-orbit event rate calculations," IEEE Trans. Nucl. Sci., vol. 54, no. 6, pp. 23222329, Dec. 2007.

[16] R. S. Wagner, J. M. Bradley, C. J. Maggiore, J. G. Beery, and R. B. Hammond, "An approach to measure ultrafast-funneling-current transients," IEEE Trans. Nucl. Sci., vol. 33, no. 6, pp. 1651-1655, Dec. 1986.

[17] D. McMorrow, T. R. Weatherford, A. R. Knudson, S. Buchner, J. S. Melinger, L. H. Tran, A. B. Campbell, P. W. Marshall, C. J. Dale, A. Peczalski, and S. Baier, "Charge collection characteristics of GaAs heterostructure FETs fabricated with a low-temperature grown GaAs buffer layer," IEEE Trans. Nucl. Sci., vol. 43, no. 3, pp. 918-923, Jun. 1996.

[18] J. D. Cressler, M. C. Hamilton, G. S. Mullinax, Y. Li, G. Niu, C. J. Marshall, P. W. Marshall, H. S. Kim, M. J. Palmer, A. J. Joseph, and G. Freeman, "The effects of proton irradiation on the lateral and vertical scaling of UHV/CVD SiGe HBT BiCMOS technology," IEEE Trans. Nucl. Sci., vol. 47, no. 6, pp. 2515-2520, Dec. 2000.

[19] J. D. Cressler and G. Niu, Silicon-Germanium Heterojunction Bipolar Transistors. Boston, MA: Artech House, 2003.

[20] P. W. Marshall, M. Carts, A. Campbell, R. Ladbury, R. Reed, C. Marshall, S. Currie, D. McMorrow, S. Buchner, C. Seidleck, P. Riggs, K. Fritz, B. Randall, and B. Gilbert, "A comparative study of heavy-ion and proton-induced bit-error sensitivity and complex burst-error modes in commercially available high-speed SiGe BiCMOS," IEEE Trans. Nucl. Sci., vol. 51, no. 6, pp. 3457-3463, Dec. 2004.

[21] M. B. H. Breese, E. Vittone, G. Vizkelethy, and P. J. Sellin, "A review of ion beam induced charge microscopy," Nucl. Instr. and Meth. B, vol. 264, no. 2, pp. 345-360, Nov. 2007.

[22] E. J. Montes, R. A. Reed, J. A. Pellish, M. L. Alles, R. D. Schrimpf, R. A. Weller, M. Varadharajaperumal, G. Niu, A. K. Sutton, R. Diestelhorst, G. Espinel, R. Krithivasan, J. P. Comeau, J. D. Cressler, P. W. Marshall, and G. Vizkelethy, "Single event upset mechanisms for lowenergy deposition events in SiGe HBTs," IEEE Trans. Nucl. Sci., vol. 55, no. 3, pp. 1581-1586, Jun. 2008.

[23] A. K. Sutton, S. D. Phillips, J. D. Cressler, M. A. Carts, P. W. Marshall, D. McMorrow, J. A. Pellish, R. A. Reed, G. Niu, and B. Randall, “Application of transistor layout-based RHBD techniques to SEU hardening of third-generation SiGe HBT logic circuits," in Nuclear and Space Radiation Effects Conf. Quebec, Canada: IEEE, 2009.

[24] E. J. Kobetich and R. Katz, "Energy deposition by electron beams and $\delta$ rays," Phys. Rev., vol. 170, no. 2, pp. 391-396, Jun. 1968.

[25] M. P. R. Waligorski, R. N. Hamm, and R. Katz, "The radial distribution of dose around the path of a heavy ion in liquid water," Nucl. Tracks Radiat. Meas., vol. 11, no. 6, pp. 309-319, 1986.

[26] W. J. Stapor and P. T. McDonald, "Practical approach to ion track energy distribution," J. Appl. Phys., vol. 64, no. 9, pp. 4430-4434, Nov. 1988.

[27] O. Fageeha, J. Howard, and R. C. Block, "Distribution of radial energy deposition around the track of energetic charged particles in silicon," $J$. Appl. Phys., vol. 75, no. 5, pp. 2317-2321, Mar. 1994.

[28] P. E. Dodd, O. Musseau, M. R. Shaneyfelt, F. W. Sexton, C. D'hose, G. L. Hash, M. Martinez, R. A. Loemker, J.-L. Leray, and P. S. Winokur, "Impact of ion energy on single-event upset," IEEE Trans. Nucl. Sci., vol. 45, no. 6, pp. 2483-2491, Dec 1998.

[29] J. S. Laird, T. Hirao, S. Onoda, and H. Itoh, "High-injection carrier dynamics generated by mev heavy ions impacting high-speed photodetectors," J. Appl. Phys., vol. 98, no. 1, p. 013530, Jul. 2005.

[30] M. Murat, A. Akkerman, and J. Barak, "Electron and ion tracks in silicon: spatial and temporal evolution," IEEE Trans. Nucl. Sci., vol. 55 , no. 6, pp. 3046-3054, Dec. 2008.

[31] A. Akkerman and J. Barak, "Ion-track structure and its effects in small size volumes of silicon," IEEE Trans. Nucl. Sci., vol. 49, no. 6, pp. 3022-3031, Dec. 2002.

[32] L. D. Edmonds, "Charge collection from ion tracks in simple EPI diodes," IEEE Trans. Nucl. Sci., vol. 44, no. 3, pp. 1448-1463, Jun. 1997.

[33] - "Analytical solutions and approximations for the equation $y \mathrm{~d} y / \mathrm{d} x=(a y+b) \cdot h(x)$ with applications to drift-diffusion," Jet Propulsion Laboratory, California Institute of Technology, Pasadena, CA USA, Tech. Rep., 2009, JPL Publication 09-13.

[34] K. M. Warren, A. L. Sternberg, R. A. Weller, M. P. Baze, L. W Massengill, R. A. Reed, M. H. Mendenhall, and R. D. Schrimpf, "Integrating circuit level simulation and monte-carlo radiation transport code for single event upset analysis in SEU hardened circuitry," IEEE Trans. Nucl. Sci., vol. 55, no. 6, pp. 2886-2894, Dec. 2008.
[35] R. A. Weller, R. A. Reed, K. M. Warren, M. H. Mendenhall, B. D. Sierawski, R. D. Schrimpf, and L. W. Massengill, "Criteria for the use of advanced physical modeling for rate prediction of single event effects in microelectronics," in Nuclear and Space Radiation Effects Conf. Quebec City, Quebec Canada: IEEE, 2009.

[36] D. McMorrow, J. S. Melinger, S. Buchner, T. Scott, R. D. Brown, and N. F. Haddad, "Application of a pulsed laser for evaluation and optimization of SEU-hard designs," IEEE Trans. Nucl. Sci., vol. 47, no. 3, pp. 559-565, Jun. 2000. 